\title{
Finite Element Analysis of Reinforced Concrete Beam Strengthened with CFRP Sheets
}

\author{
Akshay S. Harihar and Dr.D.K. Kulkarni
}

\begin{abstract}
The major challenge in the modern day civil engineering is to find a suitable method for rehabilitation and strengthening of the existing structures. One such method of strengthening is the use of strips made of fibre reinforced polymers $(F R P)$. In this paper presents the nonlinear Finite Element Analysis (FEA) that has been carried out to simulate the behaviour of reinforced concrete beams strengthened using Carbon Fibre Reinforced Polymers (CFRP) sheets. FE models were developed based on experimental tests conducted by the authors in a previous investigation. Four point bending analysis is carried out for the reinforced concrete beam. Finite element software ANSYS 14.0 is used for modelling and analysis by conducting non-linear static analysis.
\end{abstract}

Keywords--- CFRP, Flexural Strength, Finite Element Method (FEM), Strengthening, ANSYS

\section{INTRODUCTION}

$\mathrm{T}$ HERE is a huge need for repair and strengthening of deteriorated, damaged structures. There can be many reasons for the deterioration of structures, it can be due to environmental influences, inadequate design and construction or need for structural up-gradation so as to meet new seismic design requirements because of new design standards, deterioration due to corrosion in steel caused by exposure to an aggressive environment and accident events such as earthquakes, excessive deflections, and poor concrete quality, etc. or sometimes even to solve execution errors caused at the time of construction. Every project has its own set of restrictions and demands. A great deal of creativity is required to obtain the strengthening solution. Structural strengthening mainly involves increasing the ability of the structural element to resist the forces due flexure, shear, axial and torsion. One of the method of strengthening is the use of strips made of fibre reinforced polymers (FRP) bonded to the tensile face of the member which helps increasing the bending capacity, or to their side faces to increase the shear capacity.FRP plates or sheets can easily be bonded to the exterior of reinforced concrete members using the wet lay-up procedure with an epoxy resin/adhesive. They can also be used as FRP reinforcements, externally bonded sheets or plates in concrete, masonry, steel and timber structures. FRPs use synthetic fibres in polymeric matrix to provide high tensile strength. The use of FRPs has been studied by several researchers. Significant

Akshay Harihar, PG Student, Department of Civil Engineering, S.D.M College of Engineering and Technology, Dharwad, India. E-mail:akshay_harihar2000@yahoo.com

Dr.D.K. Kulkarni, Professor, Department of Civil Engineering, S.D.M College of Engineering and Technology, Dharwad, India. E-mail:dilipkkulkarni@ rediffmail.com

DOI:10.9756/BIJMMI.8184 numbers of experimental and analytical research has been carried out to understand the behaviour of reinforced concrete beams strengthened using CFRP sheets.

Finite element method is a numerical analysis method that divides the structural element into smaller parts and then simulates static loading conditions to evaluate the response of concrete. Finite element method is also known as finite element analysis is a numerical method or technique to determine the approximate solutions of partial differential equations. Many of the modern software are based on finite element method. The FEM software can take in wide range of inputs relating to fluid, thermal, electromagnetic problems. FEM is also used for analysis of structural components. It is useful in accurately predicting the response of the structure subjected to various loads. FEM is preferred to study the behaviour of concrete as it is much faster than actual experimentation and more economic.

M.R. Esfahani [1], M.R. Kianous [1], A.R. Tajari [1], studied the properties of the concrete beam strengthened using CFRP sheets. They studied the effect of reinforcing bar ratio on the flexural strength. CFRP sheets having constant width with varying length was used in the study. The different failure types in case of FRP materials are also defined in the paper. Further comparison of the experimental results with ISIS Canada and ACI 440.2R-02 is also conducted in the paper. From the investigation it was found that the equations as per the ISIS Canada and ACI 440.2 are more adequate for higher reinforcing bar ratio. N. Attari, S. Amziane, M. Chemrouk [2], studied the efficiency of the external strengthening systems for reinforced concrete beams using different FRP fabrics. They carried out comparison of strength with use of carbon and glass reinforced fibre is conducted. The results for strength, stiffness, and ductility and failure modes are discussed for the various strengthening solutions considered. Ductility ratios for different beam specimen were obtained. Analytical model is also used to determine flexural strength and the results were compared with the values obtained experimentally. From their investigation they concluded that the Strengthening using glass and carbon fibre yields similar results. Tara Sen, H.N. Jagannatha Reddy [3], in their study compared the strengthening using CFRP, GFRP and natural jute textile fibres to increase the flexural strength of the RC beam. They carried out study of failure modes, ultimate load and load deflection behaviour as well as the deflection ductility study of RC beams bonded externally with JFRP, CFRP and GFRP materials. Based on their study it was concluded that JFRP can also be used as a substitute for strengthening in place of CFRP and GFRP sheets. Significant 
research has been carried out to determine the effect of using CFRP sheets for strengthening purposes.

In this study, nonlinear finite element analysis is carried out using ANSYS which employs Newton-Raphson method to solve higher order differential equations. Many attempts have been made by the past researchers to predict the behaviour using ANSYS. The accuracy and convergence of the solution depends on factors such as mesh density, constitutive properties of concrete, convergence criteria and tolerance values etc. Thus in the present study an attempt is made to perform nonlinear finite element analysis to analyse the reinforced concrete beam. The process of analysis in ANSYS is divided into three main stages: pre-processing, solution and post-processing.

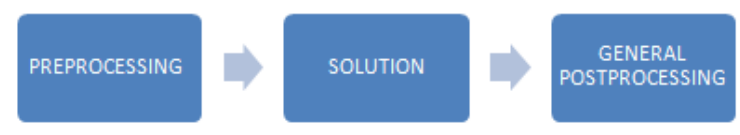

Figure 1: ANSYS Procedure

\section{PROBLEM CONSIDERED FOR THE STUDY}

Finite Element Analysis (FEA) is a method used for the evaluation of structures, providing an accurate prediction of the component's response subjected to various structural loads. The use of FEA has been the preferred method to study the behaviour of concrete as it is much faster than the experimental method and is cost effective. With the invention of sophisticated numerical tools for analysis like the finite element method (FEM), it has become possible to model the complex behaviour of reinforced concrete beams using Finite Element modelling.

\section{A. Beam Geometry}

The geometry of the full size beam is $2000 \mathrm{~mm} \times 150 \mathrm{~mm} x$ $200 \mathrm{~mm}$. The span between the two supports is $1600 \mathrm{~mm}$. Beam is simply supported by providing roller support on both the sides. Two point loads are applied at the mid-span of the beam. M30 grade concrete and Fe500 steel is used. The details of the RC beam are as shown in Fig2.

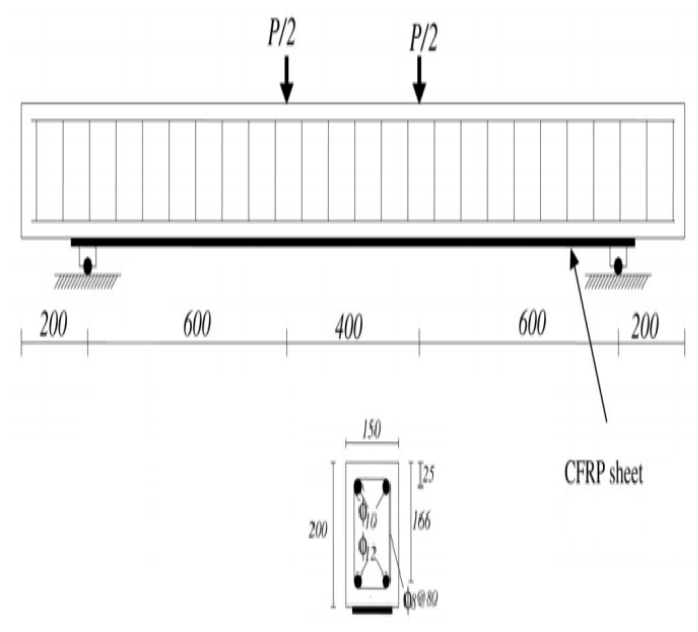

Figure 2: Beam Geometry

\section{MATERIALS}

\section{A. Steel Reinforcement}

For modelling steel reinforcement, Link180 spar element with three degrees of freedom at each node is used. Steel reinforcement in RC beam is of grade Fe500. The steel for the finite element models has been assumed to be an elasticperfectly plastic material and identical in tension and compression. Poisson's ratio of 0.3 has been used for the steel reinforcement in this study. Elastic modulus equal to 200,000 $\mathrm{MPa}$ and Poisson's ratio of 0.3 has been used for all the reinforcing bars. Tangent modulus of $20 \mathrm{~N} / \mathrm{mm} 2$ is used for reinforcement to avoid loss of stability upon yielding.

\section{B. Concrete}

The modelling of concrete is a difficult task as it exhibits different properties both in tension and compression. It is a quasi-brittle material which has relatively high compressive strength and low tensile strength. ANSYS requires the following data for defining concrete element:

- Elastic Modulus $\left(\mathrm{E}_{\mathrm{C}}\right)$ and Poisson's Ratio $(\mu)$

- Uniaxial stress- strain relation for concrete in compression

- Shear transfer Coefficients $\left(\beta_{\mathrm{t}}\right)$

- Uniaxial compressive strength $\left(f_{c o}\right)$

- Uniaxial tensile strength $\left(f_{t}\right)$

Table1: Material Properties for the Beam Model

\begin{tabular}{|c|c|c|c|}
\hline MODEL MATERIAL NUMBER & ELEMENT TYPE & MATERIAL PROPERTI & \\
\hline \multirow[t]{13}{*}{1} & \multirow[t]{13}{*}{ SOLID 65 (CONCRETE) } & \multicolumn{2}{|c|}{ LINEAR ISOTOPIC } \\
\hline & & EX & $27386 \mathrm{MPs}$ \\
\hline & & PRXY & 0.2 \\
\hline & & \multicolumn{2}{|c|}{ MULTILINEAR ISOTROPIC } \\
\hline & & STRAIN & STRESS(Mpa) \\
\hline & & 0.0003 & 7.226 \\
\hline & & 0.0006 & 12.899 \\
\hline & & 0.0009 & 17.471 \\
\hline & & 0.0012 & 21.233 \\
\hline & & 0.0016 & 24.38 \\
\hline & & 0.0018 & 27.062 \\
\hline & & 0.0021 & 29.365 \\
\hline & & 0.00219 & 30 \\
\hline \multirow[t]{6}{*}{2} & \multirow[t]{6}{*}{ LINK 180} & \multicolumn{2}{|l|}{ LINEAR ISOTOPIC } \\
\hline & & EX & 200000 \\
\hline & & PRXY & 0.3 \\
\hline & & \multicolumn{2}{|l|}{ BILENEAR ISOTROPIC } \\
\hline & & YIELD STRESS & 500 \\
\hline & & TANGENT MODULUS & 20 \\
\hline
\end{tabular}

Concrete beam is modelled using eight node Solid65 element which has three degrees of freedom at each node. The modulus of elasticity of concrete is calculated as $27386 \mathrm{MPa}$ as per IS 456:2000. Uniaxial tensile cracking stress is obtained using IS 456:2000 and is $3.834 \mathrm{MPa}$. The value of $\beta \mathrm{t}$ ranges from 0 to 1 . When there is a complete loss of shear (smooth crack) $\beta \mathrm{t}=0$, and no shear loss (rough crack) $\beta \mathrm{t}=1$. For the present study the shear coefficient is taken as 0.3 and 0.9 . Poisson's ration is assumed to be 0.2 .The concrete material properties are shown. 


\section{CFRP Sheets}

They are composite materials made of made of a two parts, a matrix and reinforcement. Carbon is the reinforcement, which provides strength. The matrix is usually and polymer resin like epoxy to bind the reinforcement together. The following data has to be input while defining the CFRP composite in the finite element model. The mechanical properties of CFRP sheet is as given in the table 2 .

Table 2: CFRP Properties

\begin{tabular}{|c|c|c|c|}
\hline $\begin{array}{c}\text { Layer } \\
\text { Thickness }\end{array}$ & $\begin{array}{c}\text { Ultimate } \\
\text { Strain }\end{array}$ & $\begin{array}{c}\text { Tensile } \\
\text { Strenght } \\
\text { (Mpa) }\end{array}$ & $\begin{array}{c}\text { Modulus of } \\
\text { Elasticity(M } \\
\text { pa) }\end{array}$ \\
\hline 0.176 & 0.0155 & 3800 & 240 \\
\hline
\end{tabular}

\section{Compressive Uniaxial Stress Strain Relationship}

The ANSYS program requires the uniaxial stress-strain relationship for concrete in Compression. The Solid65 element requires linear isotropic and multi-linear isotropic material properties to properly model concrete. The multi-linear isotropic material uses the Von-Misses failure criterion to define the failure of the concrete. Simplified stress strain relationship for concrete in compression is obtained and is shown in Fig 3.

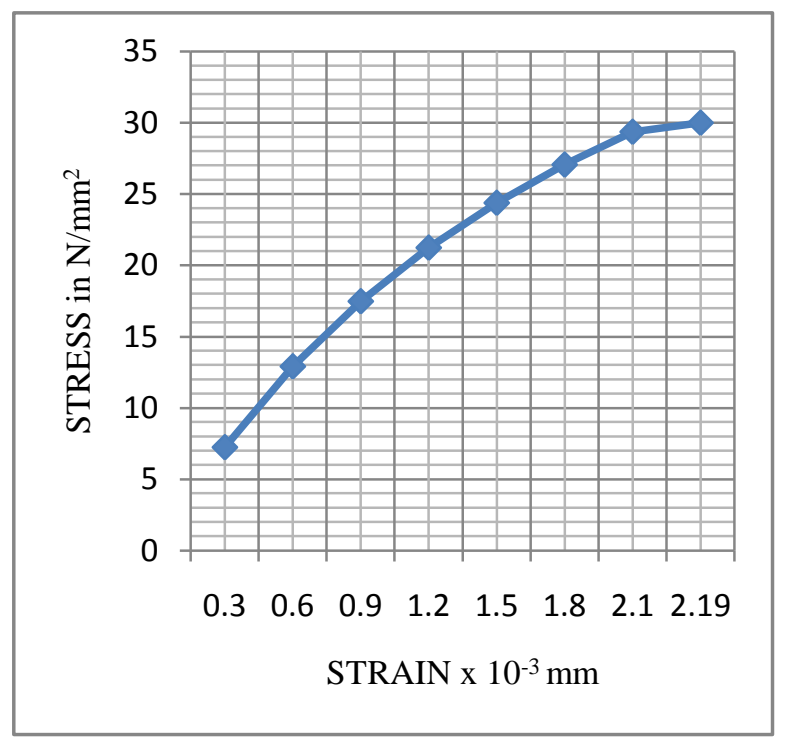

Figure 3: Simplified Uniaxial Stress-strain Curve for Concrete in Compression

\section{E. Convergence Study}

Hence a convergence test or study has to be performed to fix the number of finite elements used during the analysis. This is done by discretization of mesh and recording the solution. Convergence study is performed using plain concrete beams in a linear analysis. Ten plain concrete beams of dimensions 2000mmX200mmX150mm and same material properties are modelled in ANSYS 14 with increasing number of elements 90, 360, 480,960, 1440, 1920, 2400, 3840, 4800,
5760 using Solid65 concrete elements. A plot of load versus mid-span deflection is done and it is observed that the deflection remains constant from 480 elements to 4800 elements. The deflection is constant irrespective of the increase in elements. The observed deflection is $0.473 \mathrm{~mm}$. So the finite element model consisting of 4800 number of Solid 65 concrete elements is used for this entire study. Convergence plot is done and shown in figure 4 below.

\section{ANALYSIS TYPE}

A nonlinear structural analysis is performed to study the nonlinear material behaviour of concrete beam. ANSYS14.0 employs "Newton-Raphson" method to solve nonlinear problems. In order to predict the nonlinear material behaviour, the load is sub divided into series of load increments. The load increment can be applied over several load steps. The number of load steps required for the study is given and the time for each load step is mentioned. During the initiation of concrete crack, the steel yielding stage and at the ultimate stage where large numbers of cracks occurs, the loads are applied gradually with smaller load increments. Failure of the model is identified where the solution fails to converge even with very low load increment.
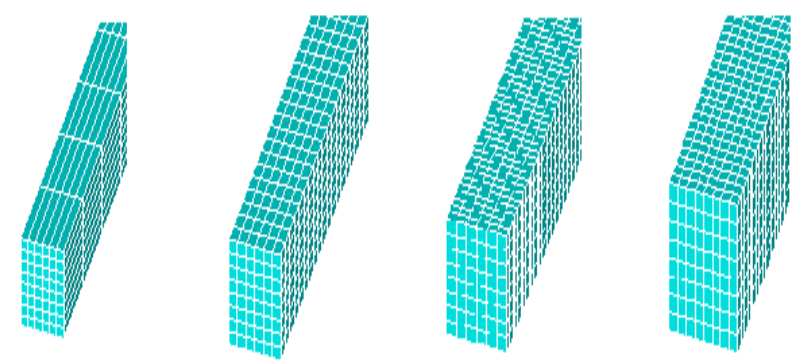

480 element

2400 elements

3840 elements

4800 elements

Figure 4: Beam Models for Convergence Study

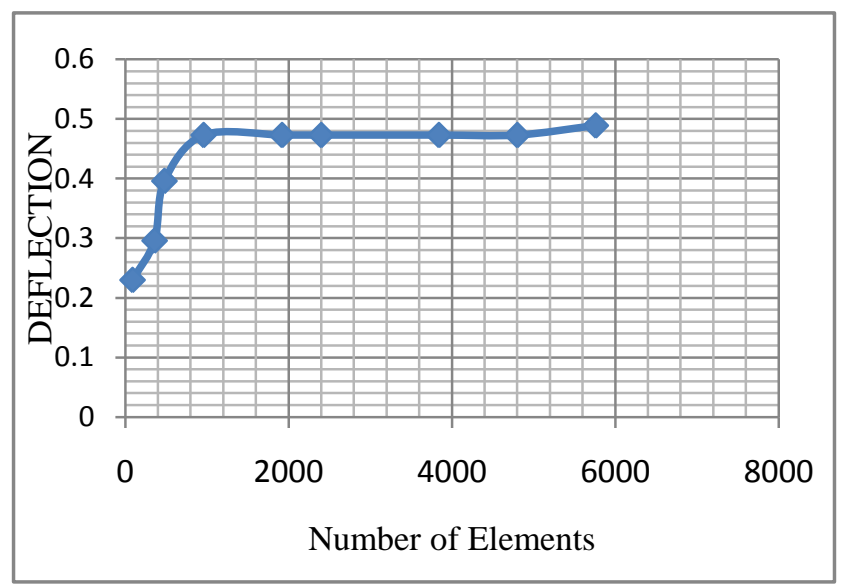

Figure 5: Results of Convergence Study 


\section{RESULTS AND DISCUSSION}

A parametric study is performed by varying the reinforcement in the beam to study the behaviour of the beam. The beam is denoted as B-a-d-bL; where " $a$ " represents the diameter of the bottom bar and " $b$ " represents the number of layers of the CFRP sheet used. As the CFRP sheet is used the flexural capacity of the beam increases significantly and the corresponding displacement reduces. The percentage increase in the strength is as given in the table 3 .

Table 3: The Percentage Increase in the Strength

\begin{tabular}{|l|l|l|l|l|l|l|l|}
\hline Specimen & Width of CFRP sheet & Layers & As & Ultimate Load $P_{u}(k N)$ & Increase in Load & \% increase & Displacement at $P_{u}($ mm $)$ \\
\hline B-12d-0L & 0 & 0 & 226 & 27 & - & - & 22.321 \\
\hline B-12d-1L & 150 & 1 & 226 & 36 & 9 & 33.33 \\
\hline B-12d-2L & 150 & 2 & 226 & 39.5 & 12.5 & 10.102 \\
\hline
\end{tabular}

\section{CONCLUSION}

The paper investigated the flexural behaviour of reinforced concrete beams strengthened by CFRP sheets. From the test results and calculated strength values, the following conclusions are drawn:

1) As predicted the flexural strength and stiffness of the strengthened beams increased compared to the control specimens.

2) As the reinforcement provided increases the strength also increases.

3) With the increase in the number of layers of CFRP sheet the strength and stiffness also increases.

4) Reinforced concrete beam can be modelled and analysed using ANSYS 14.0 software and obtain accurate results.

\section{REFERENCES}

[1]. M.R. Esfahani, M.R. Kianous and A.R. Tajari, "Flexural behaviour of reinforced concrete beams strengthened byCFRP sheets", Elsevier Ltd, Engineering Structures, Vol. 29, Pp. 2428-2444, 2007.

[2]. N. Attari, S. Amziane and M. Chemrouk, "Flexural strengthening of concrete beams using CFRP, GFRP and hybrid FRP sheets", Elsevier Ltd, Construction and Building Materials, Vol. 37, Pp. 746-757, 2012.

[3]. T. Sen and H.J. Reddy, "Strengthening of RC beams in flexure using natural jute fibre textile reinforced composite system and its comparative study with CFRP and GFRP strengthening systems", Elsevier Ltd, International Journal of Sustainable Built Environment, Vol. 2, Pp. 41-55, 2013.

[4]. J. Dong, Q. Wang and Z. Guan, "Structural behaviour of RC beams with external flexural and flexural-shear strengthening by FRP sheets", Elsevier Ltd, Composites: Part B, Vol. 44, No. 1, Pp. 604-612, 2013.

[5]. S. Hashemi and R. Al-Mahaidi, "Experimental and finite element analysis of flexural behavior of FRP-strengthened RC beams using cement-based adhesives", Elsevier Ltd, Construction and Building Materials, Vol. 26, Pp. 268-273, 2012.

[6]. A. Abu-Obeidah, R.A. Hawileh and J.A. Abdalla, "Finite element analysis of strengthened RC beams in shear with aluminum plates", Computers and Structures Elsevier, 2014.

[7]. J.A.O. Barros, S.J.E. Dias and J.L.T. Lima, "Efficacy of CFRP-based techniques for the flexural andshear strengthening of concrete beams", Elsevier Ltd,Cement \& Concrete Composites, Vol. 29, Pp. 203-217, 2007.

[8]. S. Neha, Badiger, M. Kiran and Malipatil, "Parametric Study on Reinforced Concrete Beam using ANSYS", IISTE, Civil and Environmental Research, Vol. 6, No. 8, 2014. 